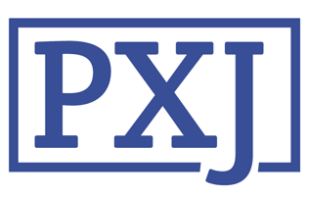

Patient Experience Journal

Volume 7 | Issue 3

Article 13

2020

\title{
How information sharing can improve patient and family experience in critical care: A focus group study
}

\author{
Jayne Garner \\ Edge Hill University \\ Sioban Kelly \\ Girendra Sadera \\ Victoria Treadway
}

Follow this and additional works at: https://pxjournal.org/journal

Part of the Health and Medical Administration Commons, Health Policy Commons, Health Services Administration Commons, and the Health Services Research Commons

\section{Recommended Citation}

Garner J, Kelly S, Sadera G, Treadway V. How information sharing can improve patient and family experience in critical care: A focus group study. Patient Experience Journal. 2020; 7(3):109-111. doi: 10.35680/2372-0247.1436.

This Research is brought to you for free and open access by Patient Experience Journal. It has been accepted for inclusion in Patient Experience Journal by an authorized editor of Patient Experience Journal. 
How information sharing can improve patient and family experience in critical care: A focus group study

\section{Cover Page Footnote}

Thank you to the staff, patients, families and carers who participated in the study. This article is associated with the Patient, Family \& Community Engagement lens of The Beryl Institute Experience Framework. (http://bit.ly/ExperienceFramework). You can access other resources related to this lens including additional PXJ articles here: http://bit.ly/PX_PtFamComm 


\author{
How information sharing can improve patient and family experience in \\ critical care: A focus group study \\ Jayne Garner, Edge Hill University jayne.garner@edgebill.ac.uk. \\ Sioban Kelly, University of Liverpool, s.kelly@liv.ac.uk \\ Girendra Sadera, Wirral University Teaching Hospital,girendra.sadera@nbs.net \\ Victoria Treadway, NHS RightCare,victoria.treadway@nhs.net
}

\begin{abstract}
The experience of being in hospital critical care has major impacts upon the patient, their family and carers. This situation is likely to be stressful, fast changing and challenging for those involved. Crucial to this encounter are factors relating to information sharing between the clinical team, the patient, family and carers. Focus groups at a UK hospital site with former patients, their families and carers provides insight into their journey and the factors that influence this. Issues that emerged included the format of information, how and who delivered this, communication transition out of critical care and leaving hospital. While participants expressed the need for personalised information, they also requested practical guidance at appropriate times in accessible formats. The encouragement from staff to keep diaries and record the patient's journey was very valued and helped recall and share progress in difficult and challenging situations. Support and coordination of care when leaving critical care and the hospital also requires planning and communication with the patient, their family and carers and relevant health care teams. The experience of patients, their families and carers is important to understand in order to ensure future services can be tailored to meet their requirements.
\end{abstract}

\title{
Keywords
}

Patient experience information, critical care

\section{Introduction}

Information is a significant factor in the critical care journey, both for the patient ${ }^{1}$ and the family. ${ }^{2}$ Critical care patients and their families have identified a lack of information/knowledge as a key factor that influences their experience of critical care. 3,4 Systematic review evidence supports the use of printed information and structured communication to improve family emotional outcomes and to reduce length of stay and treatment intensity in critical care. ${ }^{5}$ There is also evidence to suggest that personalised information provided to families in neonatal intensive care via library/knowledge services improves family satisfaction. ${ }^{6}$ It is therefore crucial that critical care patients/families have access to accurate, evidence-based information so that care can be truly patient-centred. ${ }^{7}$ Further research on patient and family experiences of information and factor impacting upon this are key to addressing these issues.

\section{Description}

Two focus groups were held at a UK critical care hospital site. Participants were recruited via a purposive sampling methodology, ${ }^{8}$ inviting local previous patients and their families and carers. Contributors to an online discussion group ICU Steps (Intensive Care Patient Support Charity) were also invited to participate. The groups were independently facilitated by two researchers $(J G-F G 1$, SK - FG2) using an 8 item question schedule exploring participant experiences of critical care and what factors impacted upon this positively and negatively, with a critical care staff member supporting each session to address any clinical queries. A total of $19(n=19)$ participants attended the groups (10 men and 9 women varying in age from 21 to 70 ), both lasting approximately 1 hour. Ethical permission was granted Via the IRAS system (IRAS ID: 180509, REC reference: 15/LO/2027).

Thematic analysis was used to identify and describe ideas emerging from the data. The coding of the data was undertaken by the project researchers with support and verification of interpretation from the project management team. The coding process was undertaken in 6 phases ${ }^{9}$ : data familiarisation, creating initial data codes, identifying themes within codes, reviewing themes, defining themes and writing a final report. All authors were involved in the iterative analysis process. 


\section{Results}

Data from both groups was integrated, with 5 themes emerging from the analysis: information format and delivery, patient and family journey, patient communication, transition, and leaving hospital.

\section{Information format and delivery}

Participants had very variable thoughts and requirements relating to information format. Paper leaflets or documents were preferred generally as a useful resource to refer back to depending on the events unfolding at the time. However, this was not always the case as some felt paper information was used as a 'fob off' by those who preferred face to face contact:

"I think to start giving people pieces of paper. I think it sort of almost says 'we can't be bothered talking to you, read that'..... Definitely. Human face to face for information. I don't really think. you want to be given bits of paper." Participant 1, FG2

Nurses were seen to be the main providers of day to day information, they were also a consistent presence which reassured families, as they built up trust in the relationship:

"You know what I found was good as well, each nurse that was on, because a different one's changing shift all the time. When they were doing something they'd explain to you exactly what they were doing... they were telling me even though I didn't know, which I thought was nice because otherwise you would be sitting there thinking 'what are they doing now?' They explained everything." Participant 8, FG2

\section{Patient and family journey}

Issues relating to cascading and sharing information between family and carers arose in discussion, including nominating a central person to coordinate patient updates and practical guidance (where to get food, parking restrictions, ward round times) were, along with experiences relating to negotiating time off work. The benefits of keeping diaries for patient and family reflection was also highlighted as key information on the journey, with patient suggesting how this could be enhanced:

'Well I couldn't take it all in, so I wrote it down. We have such a big family that when I was relaying 'well, you didn't tell me that', 'sorry I forgot' so I just made sure I wrote everything down. Even to the extent of having to phone insurance company, cancel direct debits, things like that or go to the bank, just keep a diary of who I'd spoken to, when I'd spoken to them, what the outcome was, because there is so much going on, you just can't remember." Participant 1, FG1

\section{Patient communication}

Patients who were not capable of communicating during their stay in critical care spoke in detail about their inability to understand what they were told, and their experiences relating to delirium. The need for clinical staff to repeat information was mentioned by patients, family and carers. This was acknowledged as traumatic by a number of patient participants. Patient distortion of information also arose as an issue:

"I was in a coma for 10 days and there was no way I could receive information anyway, but when I was coming round, my brain was so chewed up with delirium, I was so incapable of receiving any information, so whatever the nurses told me I couldn't take in and process, and also.... well, I didn't believe it because I was living in a world where everyone was out to get me, taking my organs and selling them, so it was a conspiracy against me" Participant 5, FG1

\section{Transition}

The processes and procedures relating to transition onto a general ward garnered many comments. Patients, in particular, found this a very challenging situation as they lost security and dedicated staff relationships, alongside increased noise and activity. Family and carers also found transition a difficult time due to inadequate and unsuitable provision of ongoing care:

"I felt as if I had been left in limbo sort of thing, they lost medication and the nurse put it somewhere when I first arrived, and no one could find it. In the end it was like the day after, it was found stuffed bebind the computer screen... but my concern was that people were coming in with all sorts of infections and every time, really nice people, but every time someone came you were worried what they had... I still had a feeding tube in and I'd only just really got used to doing that two steps to the chair and suddenly I was there and there was nothing." Participant 7, FG1

\section{Leaving hospital}

Patients spoke about how distressed they had felt after going home, and the anxiety and worry they felt about their health and the possibility of falling so seriously ill again. There was some difference in post-care experience some patients spoke about the importance of a follow up after care meeting as part of their recovery process, while some did not receive this. One family member spoke about how positive the follow up meeting had been in the patient's overall recovery:

"...that follow-up meeting helped XX to come to terms with dealing with why he was feeling the way he was. It was reassuring that this is normal, because he was thinking 'all these things that are happening to me, and all these flashbacks and things' that are still in his head now, but to know that they're stored as a memory and they'll be there. It's learning to deal with them." Participant 8, FG2

'I mean, we don't know this follow-up meeting. We wouldn't know at what point that was supposed to take place. I mean, it's the first I've beard of a follow-up meeting." Participant 7, FG2 


\section{Lessons Learned}

How patients, family and carers received information varied significantly in this study. As has been evidenced in previous research, ${ }^{10}$ this is a key factor in patient family satisfaction. Our findings highlight the importance of repeatedly providing personalised information to patient and family by clinical staff, and that addressing individual information needs at appropriate times in accessible formats is crucial. Identifying resources to effectively support this process could involve collaboration with the clinical library to ensure relevant, reliable information is provided. $^{11}$

The use of diaries and other aids such as photographs of patients while in Critical Care were seen as key moments documenting progress in the recovery process. Family and carers also found these resources helpful, as a way of recalling and sharing information as events occurred with their wider family networks. As identified in a recent review, ${ }^{12}$ encouraging staff, family and the patient to work in partnership is imperative. The joint production of diaries and other resources is a very positive way to do this.

Leaving critical care was reported as being problematic and poorly managed, creating additional anxiety for patients and family/carers worried about future provision of care and losing the close relationship they had built up with critical care staff. As previously acknowledged, ${ }^{13}$ appropriate coordination of care is crucial to improving family satisfaction. Ensuring a trusted nurse or staff member can accompany the patient as they move on from critical care would be very beneficial.

Finally, delirium and fear were very vivid in the minds of patients who had experienced this. The sense of trauma (particularly of those who had not received follow up care) was evident. Interventions such as the delirium management bundle ${ }^{14}$ and professional joint working could provide support for patients and families in future.

\section{Conclusions}

The impact of a stay in critical care has a significant effect upon the patient and their family. This can be improved by the direct delivery of timely, appropriate information, and promoting joint working between nursing staff and families in producing a patient diary. Organised follow up meetings are also an important part of the patient and family recovery process.

\section{References}

1. Young AJ, Stephens E, Goldsmith JV. Family Caregiver Communication in the ICU: Toward a Relational View of Health Literacy, J Fam Comm. 2017;17(2):137-152.

2. Wetzig K, Mitchell M. The needs of families of ICU trauma patients: an integrative review. Intens Crit Care Nurs. 2017;41:63-70.

3. Auerbach SM, Kiesler DJ, Wartella J, Rausch S, Ward KR, Ivatury R. Optimism, satisfaction with needs met, interpersonal perceptions of the healthcare team, and emotional distress in patients' family members during critical care hospitalization. Am J Crit Care. 2005;14(3):202-10.

4. Sherlock ZV, Wilson JA, Exley C. Tracheostomy in the acute setting: patient experience and information needs. J Crit Care. 2009;24(4):501-7.

5. Scheunemann LP, McDevitt M, Carson SS, Hanson L. Randomized, controlled trials of interventions to improve communication in intensive care: a systematic review. Am J Respir Crit Care Med. 2011;139(3):543-54.

6. Oliver KB, Lehmann HP, Wolff AC, Davidson LW, Donohue PK, Gilmore MM, Craven C, Roderer NK. Evaluating information prescriptions in two clinical environments. J Med Lib Assoc. 2011;99(3):23746.

7. Lane D, Ferri M, Lemaire J, McLaughlin K, Stelfox HT. A systematic review of evidence informed practices for patient care rounds in ICU. Crit Care Med. 2013:41(8):2015-29.

8. Lavrakas, P. J. (Ed.) Encyclopedia of survey research method. 2008. Thousand Oaks, CA: SAGE.

9. Braun V, Clarke V. Using thematic analysis in psychology. Qual Res Psychol. 2006;3(2):77-101.

10. Khalaila R. Patients' family satisfaction with needs met at the medical intensive care unit. $J$ Adv Nurs. 2013;69(5):1172-82.

11. Esparza JM, Shi R, McLarty J, Comegys M, Banks $\mathrm{DE}$, The effect of a clinical medical librarian on inpatient care outcomes. J Med Lib Assoc. 2013;101(3):185-191.

12. Mitchell ML., Coyer F, Kean S, Stone R, Murfield J, Dwan T. Patient, family-centred care interventions within the adult ICU setting: an integrative review. $A m$ J Crit Care. 2016;29:179-193.

13. Stricker KH, Kimberger O, Schmidlin K, Zwahlen M, Mohr U, Rothen HU. Family satisfaction in the intensive care unit: what makes the difference? Intensive Care Med. 2009;35(12):2051-2059.

14. Bannon L, McGaughey J, Clarke M, McAuley DF, Blac kwood B. Designing a nurse-delivered delirium bundle: what ICU staff, survivors and their families think. Aust Crit Care. 2018;31(3):174-179. 